\title{
A NEW SET OF BIRD GUIDES
}

BERNARD GOLLOP, 2202 York Avenue, Saskatoon, Saskatchewan. S7J 1J1

In 1987 a new set of guides was made available to birders:

FARRAND, JOHN, Jr. 1987. How to identify birds. An Audubon handbook. McGraw-Hill, N.Y. 317 pp., $8.75 \times$ 4.50 in., $700+$ color photos. $\$ 19.95$

FARRAND, JOHN, Jr. 1987. Western birds. An Audubon handbook. McGraw-Hill, N.Y. 496 pp. 1314 color photos. 168 drawings. \$19.95

FARRAND, JOHN, Jr. 1987. Eastern birds. An Audubon handbook. McGraw-Hill, N.Y. 496 pp. 1354 color photos. 179 drawings. \$19.95.

I am largely commenting here on this publication's pertinence to Saskatchewan birds as listed in the 1983 checklist, plus Clark's Grebe and Rednaped Sapsucker. ${ }^{4}$ For brevity, the three volumes will frequently be referred to as $\mathrm{HTI}$ for the How-to-Identify volume, $\mathrm{WHb}$ for the Western handbook; EHb for the eastern handbook. The number following an abbreviation is the pertinent page. Emphasis is on WHb because it is recommended for Saskatchewan.

\section{All that glitters is not gold.}

Since 1977 birders have been showered with 11 major volumes on identification - one per year!' 25678 Six sets have been involved, including the present one, and three have been based on photographs and have involved John Farrand as author or editor.' 2 None, including this one, has been as good an identification guide as the three sets based on paintings. ${ }^{567}$ However, the present series claims a "new approach to birding" and it includes the best and most extensive set of mini-photographs ever compiled. As a group, their color and sharpness are unsurpassed. The three-volume Master Guide had 1245 photos; these handbooks probably have twice that many different photos (about 3370 in total, including duplicates). The western and eastern volumes of this set are worth getting (preferably as a gift) for the photos alone. In buying $\mathrm{WHb}$ and $\mathrm{EHb}$, much more often than not you get twice as many different photos of a species. However, for the difficult-to-separate shrikes, the six pictures in WHb are the same as in EHb - except for color reproduction.

\section{How-to-identify-birds Handbook}

This volume is the most interesting of the three. It is the key to the author's "new approach to birding," which he does not define anywhere that I can find, other than to say of $\mathrm{HTI}$, "This book tells you how my system works" (p. 17). The book has more than 700 photos of habitats and birds that are used as an illustrated dictionary of six chapters: habitat, size, behavior, shapeand-posture, color-and-pattern, and voice (the last restricted to songbirds and doves). Except for voice, each of these sections has 8 to 10 two-page charts that are the stepping stones in this "new approach to birding."

The author himself seems unsure of the method he proposes. In HTI (p. 108) he writes "... you narrow down the number of birds until you reach the 
species you have seen." But later ( $p$. 120) he states "... identifying a bird is a process of elimination that leads from the known to the unknown ..." There seems little point in trying to end up with an unknown.

\section{Habitat}

In this section habitats are defined by photos of luxurious color and unbelievable clarity. There are 152 photos, mostly of scenery, but almost a third are portraits of pertinent birds. However, considering the number of bird photos in the three volumes, all with habitat in the background, it would seem more appropriate to have included more or larger habitat shots.

The "new approach to birding" puts habitat first in the identification process. I think this is a major fallacy. A species is seen in many habitats in the course of a year but is seldom seen in more than three recognizable plumages and, with few exceptions, it varies little in size. When I see a bird I cannot identify, I try to determine its size, color and shape before anything else. I don't care what habitat it and I are in.

"I have listed all North American bird groups, as well as very striking species, according to the habitats in which they are normally found" (italics mine; HTI p. 21). This is not good enough. The author's idea of normal habitats matters less than where birders may normally see a species. Beginning birders are told not to look for many northern breeding species - most warblers and sparrows - Merlin, magpies, Clay-colored Sparrows, etc., in residential areas, which happens to be where I normally and regularly see these species.

Habitat contradictions also occur in the texts. In the habitat section of HTI (p. 77) Townsend's Warbler is shown as typical of residential areas but these sites are not listed for the species in WHb (p. 365). In HTI (p. 177) a mark appears under goshawk for Open Habitats but in the species treatment, these are not mentioned (WHb p. 223, EHb p. 223).

\section{Size}

A stated cornerstone of this different approach to birding is a new definition of size that combines confusion and impracticability. "When I refer to size, I mean the size of a bird's body, and not its overall length and its shape... Considering the overall length of a bird by including a long neck or tail would make it difficult to group birds by size,

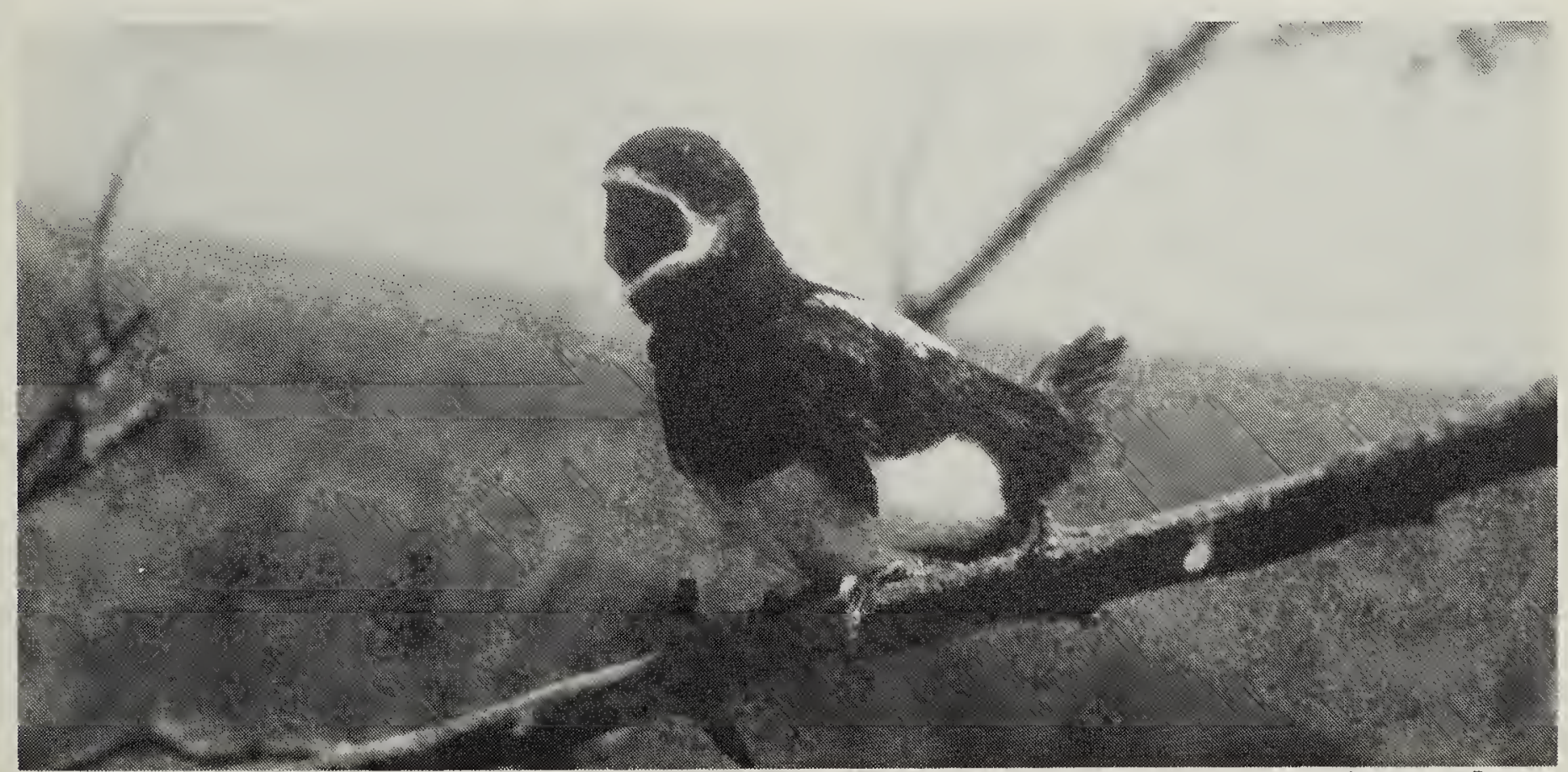


because we would be dealing with individual, subjective impressions rather than with facts" (HTI p. 78). As I interpret this statement, the author is saying that visualizing and comparing body length, i.e., without head, neck and tail, is objective, whereas looking at total length is subjective, making it difficult to compare one species' total length with another's. Good luck, novice birder! Most veteran birders look at total lengths.

We then read in WHb (p. xi) that "The Field Marks section begins with the average body length of the adult ..." (italics mine). Not so! The lengths given in this section are the same as those given in the National Geographic (NGS) guide as "Average length from tip of bill to tip of tail." "The author now apparently is using the very measurement he rejected in HTI.

Seven size categories are proposed: very small, sparrow-, robin-, pigeon-, crow- and goose-sized, and very large. Straightforward? Not until you completely revise your thinking and remember that these categories purportedly refer to headless, neckless and tailless bodies. As a result, at $12 \mathrm{in.}$ (total length) we find Mourning Dove and our two cuckoos classed as "Robin-sized," while Merlin, Upland Sandpiper and nutcracker are "Pigeon-sized." At 14 in. Chukar and Greater Yellowlegs are "Pigeon-sized" but Rock Ptarmigan and stilt are "Crow-sized." Furthermore, Cackling Goose which is "only about the size of a Mallard" ("Crowsized") is labelled "Goose-sized" (WHb p. 119).

Given a revolutionary definition, one should be able to assume that a key species is near the middle of its size range, but, if total lengths are any indication, this is not the case. Crowsized birds go from $2.56 \mathrm{in}$. shorter to 6.5 in. longer than an average crow; pigeon-sized birds in this book are the same length as or longer than Rock Doves, while all goose-sized birds are the same length as or shorter than Snow Geese. A final problem is that assignment of a single (average) length to a species gives the illusion that it fits into only one category. However, on the basis of the range in total lengths given in the Master Guide, almost as many "Crow-sized" Short-eared Owls and Spruce Grouse, for instance, are actually in the pigeon- as in the crow-sized category. ${ }^{2}$

While the author suggests that mastering his seven size classes is a major step in identification, I believe he puts too much emphasis on it without sufficient warnings. Many birders have had the experience of finding that Bohemian Waxwings appear sparrow-sized one day and robin-sized another. Furthermore, the five smaller classes end up being separated from each other by a half inch or less - an impossible distinction to make in the field.

The first chart combines Habitat and Size, listing 154 groups and species of North American birds under seven size classes in the left column of each left page and 23 habitats across the top (HTI pp. 110-112). From this, one learns such things as: warblers (43 unspecified species) use 13 habitats, American Robin uses 10, and one magpie (unspecified) uses 3 habitats (whatever the other magpie is, it is not listed; HTI p. 116). Reading the charts another way, one finds that "Open Country, Grasslands, and Groves" are used by 25 groups of sparrow-sized birds, representing an unknown number of unspecified species. Not very useful for the beginning birder studying a small unidentified bird in an aspen grove. Not only is this chart of little practical value in identifying a bird but it is also largely redundant because each of the $\mathrm{Be}$ havior, Shape-Posture and Color-Pat- 
tern charts is more specific in its identifications and incorporates the seven size classes and five major habitat groups.

\section{Behavior and Shape and Posture}

These two sections in HTI illustrate some postures not found in field guides and these are useful. However, some behaviors are not amenable to the three photographs allotted, e.g., "Flushing" (under Wings), "Erratic Flight," "Skulking," "Slow Foraging" and "Rapid Foraging." "Mobbing Predators" appears under "feeding" and a glance at the birds listed indicates that curlews, magpies, redpolls and others have been left out. "Wing-flashing" on the ground is illustrated by a mockingbird ( $\mathrm{HTI}$ p. 134) and shown as a "Giveaway Field Mark" in the chart (HTI p. 175) but is not mentioned in the species treatment (WHb p. 425).

Three pictures are usually used to demonstrate a character, but there are indications that there may have been a shortage of photos. For "Noisily Scratching Leaves," all show Rufoussided Towhee; "Holding Neck in an S-curve," Tricolored Heron only (on the next page is a stilt with an S-curved neck but stilt is not shown under this behavior in subsequent charts). In addi-

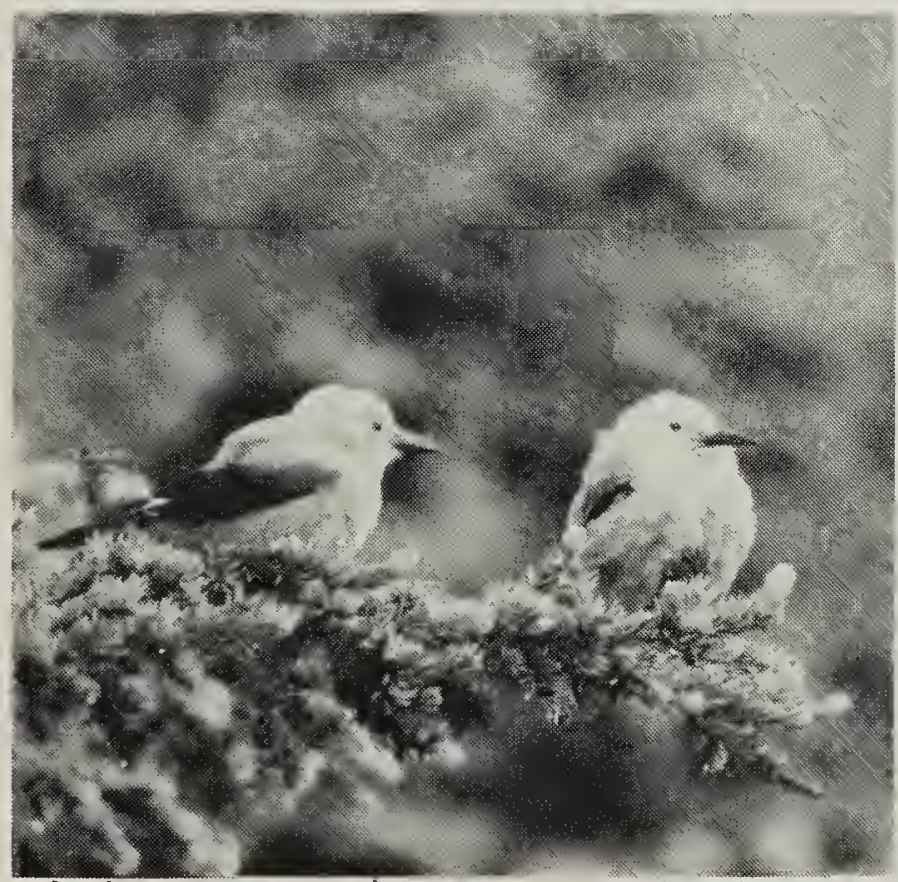

Clark's Nutcracker

Juhachi Asai tion, some of the demonstration photos are irrelevant to the pertinent character: "Robbing Food From Other Birds" shows three photos of a Long-tailed Jaeger alone in flight; "Flying With Slow Wingbeats," three photos of Great Egret; "Bill-sweeping," all pictures are of an avocet, apparently not bill-sweeping. Obviously, in dealing with shape and posture, the author has restored heads, necks and legs to the birds.

\section{Color and Pattern}

This is an interesting conglomeration with no explanation of why it is restricted to ducks, woodpeckers and songbirds. Unfortunately, the selection of species to illustrate characteristics is subjective and inconsistent. For in stance, Mallard and shoveler are examples of "Green Head" while the green-headed Red-breasted and Common mergansers are "Black-and-White Pattern." "Yellow Breast" shows Canada and Kentucky warblers; why is the former not under "Yellow [with] Black on Breast" and the latter "Yellow [with] Dark Mask?" Blue Jay is listed as "Solid Blue Overall." Shrike exemplifies "Black-patterned - Blackand-White Markings" while 12 pages later the nutcracker illustrates "Gray Gray and White."

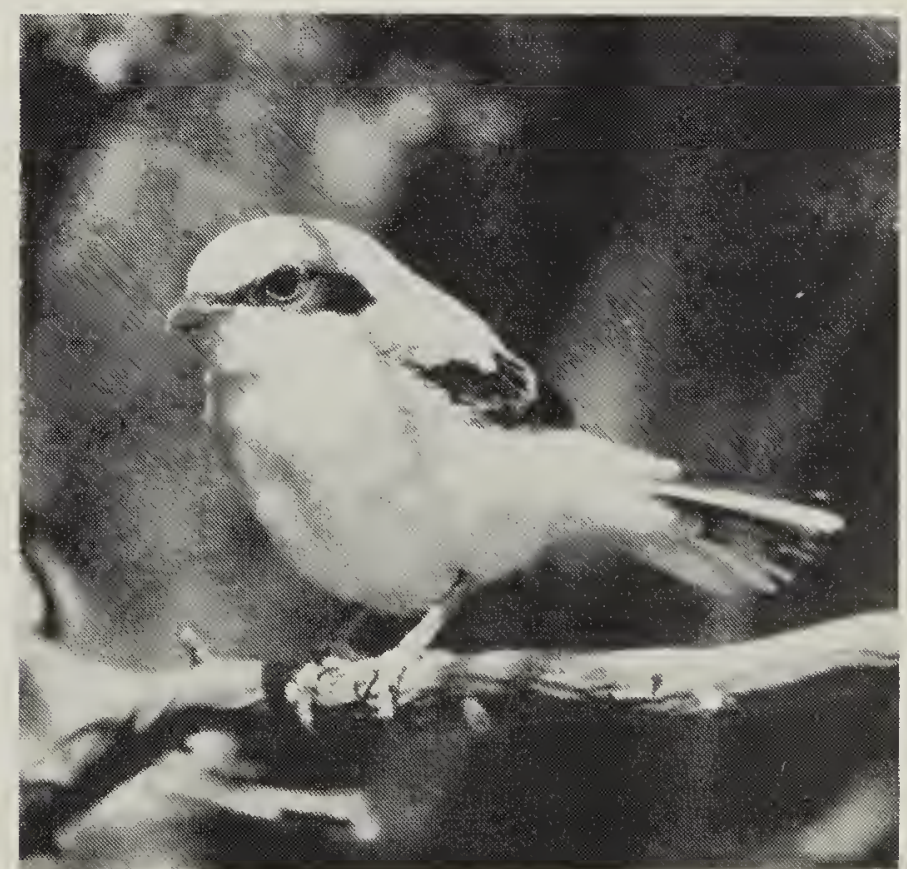

Loggerhead Shrike

Gary W. Seib 


\section{The Process}

As I understand the "new approach," if you debark from a plane in the boreal forest and see a "Sparrow-sized" bird, you turn to the Habitat and Size chart in $\mathrm{HTI}$ and find that there are 131 species of this size found in this habitat. You then turn to the next chart - Behavior. (A long aside: Why is Behavior before shape and color? "... because a bird's behavior can sometimes be seen at distances so great that you can't make outs its color or shape." The example to prove the point is: "... one can distinguish the Greater Yellowlegs and Lesser Yellowlegs ... from the window of a speeding train. The Lesser Yellowlegs always probes for its food or picks it from the surface, but the Greater often feeds by sweeping its bill back and forth through the water. This distinctive behavior can be seen from so far away that it can be used to spot a Greater Yellowlegs even when shape and color are all but invisible" (HTI p. 122). On HTI pp. 161 and 163 bill-sweeping (side-toside) is shown as a "Giveaway Field Mark" for both Greater Yellowlegs and avocet. One wonders how many faraway avocets the author has recorded as Greater Yellowlegs. This example is a better justification for downplaying behavior than for rating it so highly. End of aside.)

Returning to what is actually a Behavior/Habitat/Size chart, the birder finds four pairs of facing pages for "Sparrow-sized" birds, with 13 to 29 behaviors on left pages and about 23 species and groups across the tops of each pair of pages. These s/he works through, hoping the bird performs one of the behaviors listed.

This time-consuming search is then repeated through similar charts on "Shape and Posture" and "Color and Pattern," and descriptions of 12 voice types. While only a caged canary would sit still for all this, the birder can theoretically take $60 \%$ of Saskatchewan birds to the species level. This does not strike me as an "easy-to-learn method for quick and accurate identification of birds."

The value of HTI would have been considerably enhanced if, after going through the clues and coming up with a species or group name, the birder could read beside that name the pages treating the bird(s) in a regional volume. Space exists to do this, using boldface and plain type to separate WHb and EHb. The author's solution is to provide an impractical index, alphabetical by 62 artificial groups (not bird families). One such group is "Meadowlarks Brown, open country birds with long pointed bills. Walk on ground and flush when disturbed" (HTI p. 295). Could this not equally fit Marbled Godwit and Upland Sandpiper? (Incidentally, in the color charts, meadowlarks appear under "Yellow.") This index is needlessly frustrating. For instance, crossbill is not under $C$ and one has to know enough taxonomy to realize that crossbill will be found under "Finches" (HTI 300). Another problem is the lack of indentation and inconsistent use of dividing lines; as a result, one has the impression that Redhead is a merganser (HTI 299). The beginning birder has to know that chat is a warbler in order to find it. However, waterthrushes are not under warblers.

The how-to handbook has an appendix of birdfinding guides that fails to include any Canadian publications, including $A$ Bird-finding Guide to Canada.'

Had the producers of this volume wanted to be truly innovative, they would have expanded and computerized the charts. The birder could then enter the characteristics detected in the field or at home - and the com- 
puter would calculate what species s/he was seeing.

This volume presents an interesting approach, but its information varies from being seriously flawed to needing considerable refinement. In the meantime, the beginning birder might better spend a lot of time studying pictures and text in a good field guide and going out with people who know birds - always being at least a little skeptical.

\section{Western and Eastern Handbooks}

The introductory pages are the same in both guides except for geographical accommodations. Pages 20 through 477 provide "picture-and-text accounts of over 460 species" in each guide. Each species fills a page, allowing only two species at a time to be compared simultaneously. The upper fifth contains species name, size category, one to five habitats used, a size bar and an inset color photo or black-and-white drawing of a key character. The middle third of the page has one to four color photos and the bottom third is text under the heading Field Marks (incl. length, plumage, voice), Similar Species and Range.
The claim for $\mathrm{WHb}$ is that coverage includes "birds regularly found" in "the states between the Pacific Coast and the western Great Plains ... as well as Saskatchewan," but excluding "the arctic northern parts of ... Alberta and Saskatchewan." Really! The eastern handbook "does not cover the birds of ... Saskatchewan." In fact, EHb has 17 more Saskatchewan species illustrated than WHb.

How complete is the coverage for this province? Four hypothetical species, as expected, are not even mentioned in either volume: Common Pochard, Eskimo Curlew, Sharp-tailed Sandpiper and McKay's Bunting. All are illustrated in the National Geographic Society (NGS) guide. Another 39 species are not mentioned in $\mathrm{WHb}$ and 34 in $\mathrm{EHb}$. A further 24 species are mentioned but not illustrated in $\mathrm{WHb}$ and 12 in $\mathrm{EHb}$. Thus 67 species $(18 \%)$ on the Saskkatchewan checklist are not illustrated in $\mathrm{WHb}$, and $50(13 \%)$ in $\mathrm{EHb}$. Among the "regularly occurring" species not mentioned in WHb are Piping Plover, Brown Thrasher, 12 confirmed species of warblers, Le Conte's, Sharp-tailed and Harris' sparrows. Species and iden-

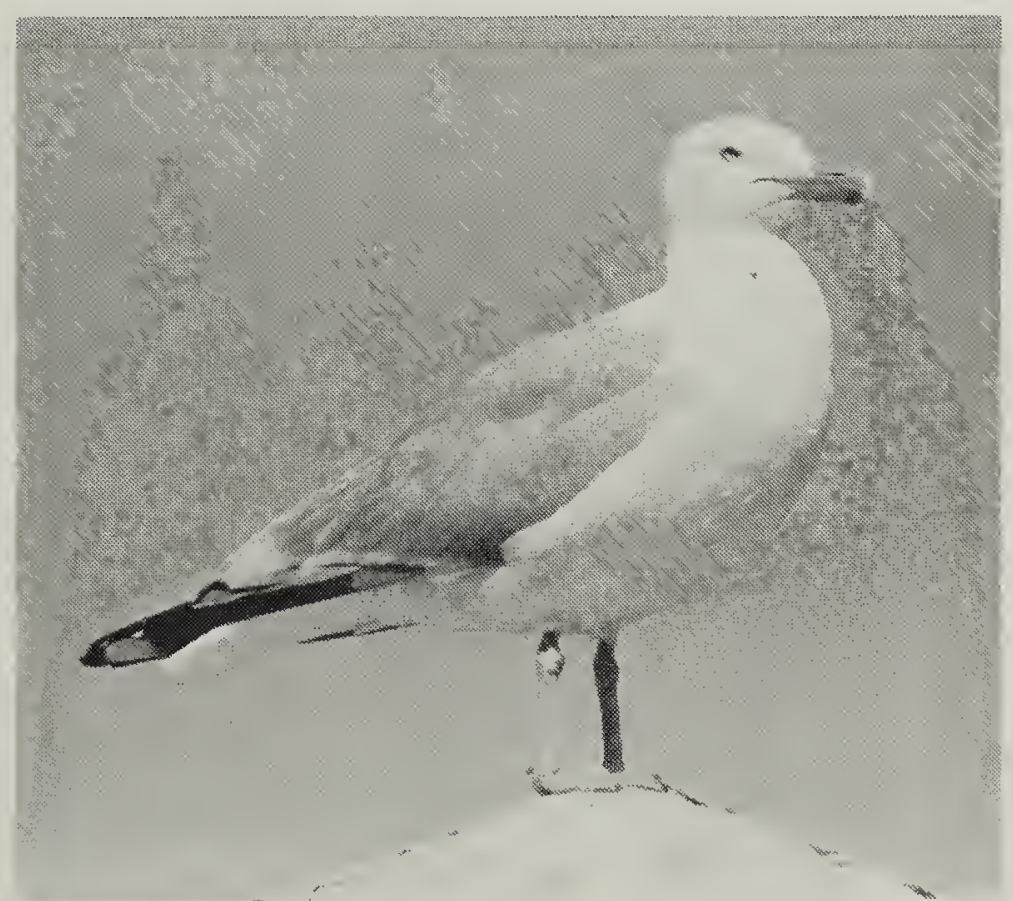

Herring Gull
Robert J. Long

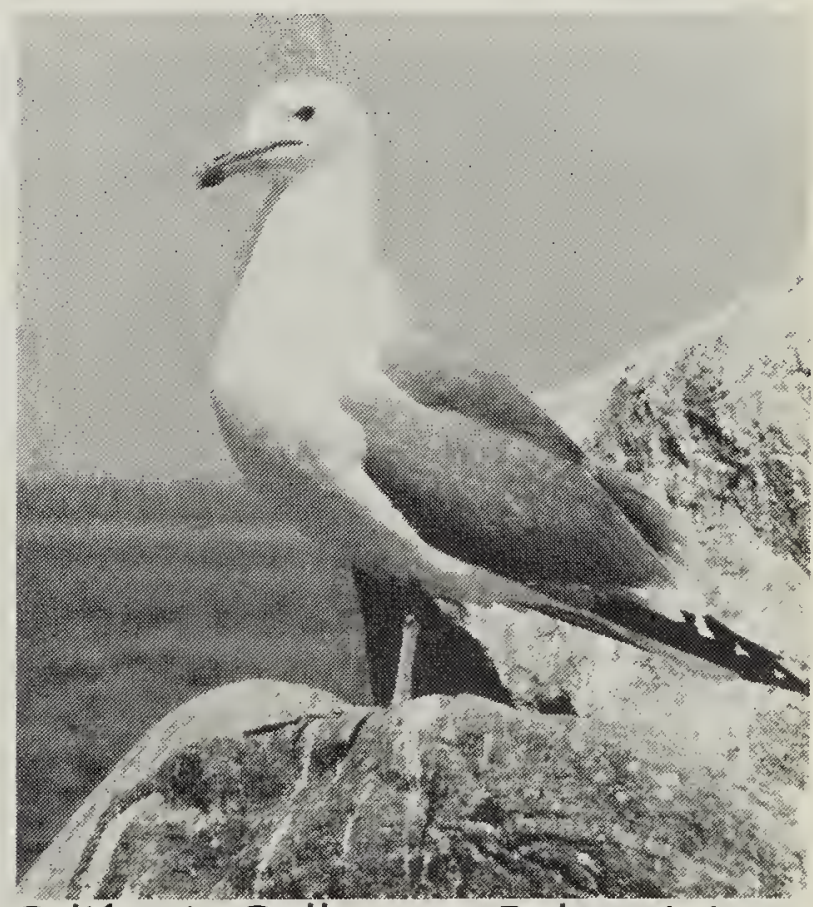

California Gull
Robert J. Long 
tifiable Saskatchewan subspecies mentioned in $\mathrm{WHb}$ but not illustrated include Clark's Grebe, Yellow-shafted Flicker, Blue Jay, Sprague's Pipit, three breeding species of warblers, Rosebreasted Grosbeak, Baltimore Oriole and Slate-colored Junco. It might be argued that some of these species are excluded because they breed in "arctic" Saskatchewan, but all either breed or migrate regularly through the tropical parts of the province.

\section{Plumage descriptions}

With one page per species, you might expect thorough descriptions of species and similar-species comparisons. Identification data in the text are nothing special. Furthermore, they are relatively verbose compared to the NGS guide. In spite of that, NGS devotes more words than $\mathrm{WHb}$ to such difficult groups as Red-tailed/Swainson's hawks, California /Ring-billed/Herring gulls, Artic/Common /Forster's terns and Least/Willow/Alder flycatchers.Among omissions is mention of the white tufts on both sides of the lower back of Olive-sided Flycatcher. The "cheek" - a key plumage character in separating meadowlarks - is not labelled in the diagram showing parts of a bird.

\section{Ranges}

The set is behind the times in using words, instead of maps, for distribution. The ranges are skimpy and they are ambiguous about occurrence in the Prairie Provinces, e.g., Whooping Crane "nests in west-central Canada." In some cases they are wrong, e.g. in WHb and EHb Double-crested Cormorants do not breed in this region but Arctic Terns breed throughout it. According to WHb, Franklin's Gull and Black-billed Cuckoo do not breed in Alberta nor do Red-naped Sapsucker, MacGillivray's Warbler or Brewer's Sparrow nest in Saskatchewan. Due to omission of a phrase found in $\mathrm{EHb}, \mathrm{WHb}$ states that
Burrowing Owls do not breed in the Canadian Prairies.

\section{Illustrations}

In still another way, these titles fall below the standard set by two previous guides sponsored by the National Audubon Society. In Peterson's and Master guides, pointers on the illustrations highlight distinctive field marks. No such useful aid to identification occurs in this set.

In a good field guide, most species are shown from the side with details of at least half of a bird's front clearly shown. In this, as in other photographic guides to date, particularly with songbirds, too many photos show more back than front and, when the angle is right, the front is too often shaded. There are also other examples of problems with photos, e.g. the color of Connecticut Warbler in $\mathrm{EHb}$ and the blurred Blue Grosbeak in $\mathrm{WHb}$ and $\mathrm{EHb}$.

How many different illustrations are there for each species? In WHb: 17 Saskatchewan species have one illustration, 89 have two, 128 have three, 71 have four and 3 have 5 . However, as in all the major photographic guides to date, when a photo is not available, a key plumage is not illustrated and, in this one, photos are repeated, sometimes reversed or enlarged, giving the impression of new pictures. In both WHb and Ehb, "Adult Male" and "Male" ducks apparently occur only in breeding plumages; there is no mention of their female-type eclipse feathering. For many species illustrated by three photos (excluding the inset), one picture is double-sized and is a completely unnecessary portrait, usually a bust, of one of the plumages already illustrated. Sometimes it is simply an enlargement of one of the adjacent photos. The space would have been much better used by presenting the other two photos in larger format or by showing another 
plumage. In many cases the inset photo is also an enlargement of the head from one of the other photos. In the case of the two redpolls in $\mathrm{WHb}$, the same inset is used for each species!

But the heart of a field guide is the number of plumages that are well illustrated. For some difficult-to-separate species, this number in $\mathrm{WHb}$ is significantly smaller than in NGS, the ratios for those species (WHb/NGS) standing as follows: Red-tailed and Swainson's hawks 3/9; jaegers 4/13; California, Ring-billed and Herring gulls $7 / 16$ and two shrikes $3 / 5$. Because not all species for the following comparisons are in $\mathrm{WHb}$, the numbers are from EHb: Semipalmated, Least, Western, Baird's and White-rumped sandpipers 10/14; Arctic, Common and Forster's terns $3 / 14$; Veery, Wood, Hermit, Swainson's and Gray-cheeked thrushes 5/10. Finally, both volumes are required for a MourningMacGillivray's-Connecticut warbler comparison because not all occur in either volume: 5/10. Furthermore, breeding adult male plumages dominate (but are not shown for the three phalaropes). As a result, $\mathrm{WHb}$ and $\mathrm{EHb}$ are more suited for identification in spring and summer than fall and winter.

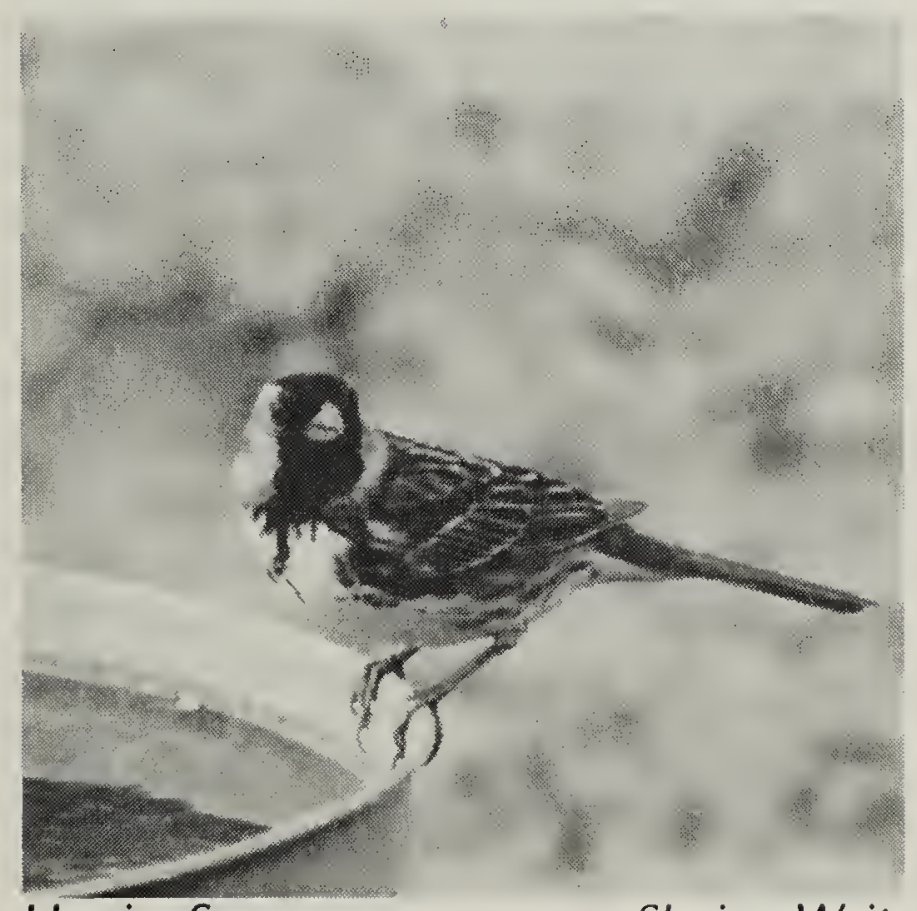

Harris Sparrow

Sheina Wait
Photographic guides are noteworthy for their disregard of scale and this may mislead some users. Two examples on facing pages in $\mathrm{WHb}$ give the impression that avocet is smaller than stilt (pp. 140-141) and nutcracker is larger than magpie (pp. 290-291).

\section{Sequence of species}

"To help you refer to a species quick$l y$, the picture-and-text accounts are organized according to similarities such as habitat, lookalikes, and related species" (WHb p. x). In fact, species are broadly divided into water-oriented and land birds but groups and species within these divisions are haphazard and unpredictable. The $\mathrm{WHb}$ begins with gulls, terns and later puts Piedbilled Grebe among the ducks; $\mathrm{EHb}$ begins with terns, gulls and puts Piedbilled in with other grebes. A glance at the Contents shows that the criteria for organization apparently changed from WHb to EHb after kingfishers, e.g. pipits-longspurs, larks, meadowlarks and orioles in the former and hummingbirds, chickadees, flycatchers and woodpecker in the latter.

Furthermore, pipits-longspurs are more than 180 pages from other sparrow-sized open-country-grassland little brown birds. For raptors in $\mathrm{WHb}$, part



Lapland Longspur

Sheina Wait 
of the sequence is: buteo, falcon, two kites, two accipiters, buteo, accipiter, buteo, falcon, buteo, falcon, two buteos and two falcons. Neither habitat nor size nor look-alikes explain the sequence. In $\mathrm{EHb}$, the order is different. In EHb Dickcissel is between McCown's and Lapland longspurs; in WHb it is 195 pages from the nearest longspur. In WHb Golden- and Rubycrowned kinglets are on the same page; in EHb they are 45 pages apart. Why is the sequence ducks-swans-geese in the body of WHb, ducks-geese-swans in $\mathrm{EHb}$, and swans-geese-ducks in unnumbered pages 1-4 of both volumes? Etc., etc., etc.

Behavior hardly seems adequate justification for separating species that look alike, are the same size and are assigned to the same habitat. For instance, I doubt that any birder is helped by inserting Black-and-white Warbler between woodpeckers and nuthatches and 143 pages from its look-alike, the Blackpoll in EHb. In WHb the Blackand-white is described, but not illustrated, under Blackpoll.

The author claims that a knowledge of taxonomy is not needed for his system. Not so, as noted previously for crossbills and bird groups. Furthermore, taxonomy and look-alikes are often closely associated and most beginning birders have probably been exposed to enough taxonomy through checklists and regional bird books to use it profitably in a field guide. Within the basic division of water and land birds, a taxonomic sequence would have been more logical (with some exceptions) than the organization found in these regional volumes. Everyone from beginning to expert birder would then have had a good chance to find a species or group by going directly to the text.

\section{Identification Errors}

The major misidentification that I noted in WHb [2] is a female-plumaged pintail in flight labelled as a female Mallard. Immature kittiwake and nonbreeding white pelican are referred to as breeding adults. The treatment of Common Grackle implies that males and females look identical. While not exactly an error, in at least five cases in WHb, one species' name at the top of a page covers two species, e.g. "Acorn Woodpecker" illustrates Red-headed as well.

\section{Numbering}

There are also some annoying features in the numbering of various features. Where there is more than one photo, they are numbered. But in about 87 of 281 such cases, the photos are not treated in the text in the same order as numbered, requiring constant attention to the sequence. The absolute need to have facing pages mirror each other and to maintain a rigid numbering system are apparently the causes. Page numbers: what could be more straightforward? Yet, in both WHb and $\mathrm{EHb}$, only even Roman-numeral pages are designated; 13 pages between xvi and 14 are unnumbered - except in the index, and only one page between 480 and 496 is numbered. Furthermore, page numbers in $\mathrm{WHb}$ and $\mathrm{EHb}$ appear at the bottom of each page, while in HTI they are at the top and then only on odd-numbered pages - a particularly frustrating feature since the index refers to the two-page charts only by even-numbered pages.

Trees could have been saved. With no concern for the conservation of trees or the birder's purse or convenience in the field, the author, publisher and sponsoring agency have produced a set that requires both $\mathrm{WHb}$ and $\mathrm{EHb}$ for many areas of the continent and for many travelling birders (combined weight $1100 \mathrm{~g} ; 2.2$ lbs.). In fact, the two 
handbooks could have gone into one volume.

As it is, the same 378 species are treated in each regional book; an additional 156 appear in WHb only and 124 in EHb only. More than half of the species are duplicated! Take the western handbook and add the 104 pages it takes to cover the 124 species not included and the new volume would treat North America in about 620 pages. This would be $60 \%$ of the current 1026 pages - a significant saving in trees, cost and weight. (The earlier western Audubon photographic guide ran to 855 pages. $^{8}$ )

Photographic guides will continue to be inadequate for bird identification until they put four or more similar-looking species on a page with several plumages for each and pertinent text on the facing page. The western and eastern handbooks combined deal with about 658 species, not all illustrated; the NGS guide depicts all of these and 150 more in one volume. ' The cost of the former two is $\$ 40$, the latter $\$ 27$ less when you can get it on sale - and you get more pictures per species.

\section{Editing}

In most publications, editing errors are inconsequential, but not in this set. Unbelievably, three birds in WHb are given page numbers in the index but do not occur in the text: Bewick's and Mute swans and Sedge Wren; in EHb Chukar suffers the same fate. On HTI p. 177, Northern Grosbeak (a nonexistent species) apparently refers to Northern Goshawk. The index in EHb is alphabetical and apparently accurate. In WHb it is not; two examples are: Golden-Plover preceding Goldeneye and Black-throated Gray above Black-andwhite Warbler. In most cases hyphenated names are cross-referenced but neither Storm-Petrel nor WoodPewee appear under $\mathrm{P}$ in $\mathrm{WHb}$. In $\mathrm{WHb}$ the pages for Great Blue Heron and Great Egret have been transposed and two page references are given for "Black-Hawk, Common" but only one for "Hawk, Common Black-."

\section{Conclusion}

All that glitters is not gold. Or, pretty pictures, a reputable sponsor and superlative advertising do not an effective bird guide make. This series should be bought only as a supplement to one or two real identification guides.

\section{Acknowledgements}

My thanks to Mary Gilliland, Jim Wedgwood, Ed Driver and Phil Taylor for their assistance in preparing this article.

' BULL, JOHN and JOHN FARRAND, Jr. 1977. The Audubon Society field guide to North American birds. Eastern region. Knopf, N.Y. 775 pp.

2 FARRAND, JOHN, Jr., Ed. 1983. The Audubon Society master guide to birding. 3 vols. Knopf, N.Y. 447, 398, 399 pp.

'FINLAY, J.C. 1984. A bird-finding guide to Canada. Hurtig, Edmonton, AB. 387 pp.

${ }^{4}$ KREBA, ROBERT 1983. Field checklist of Saskatchewan birds. Mus. Natural Hist., Regina, SK. 6 panels.

${ }^{5}$ PETERSON, R.T. 1980. A field guide to the birds east of the Rockies. Houghton Mifflin, Boston. $384 \mathrm{pp}$.

"ROBBINS, C.S., BERTEL BRUUN and H.S ZIM 1983. A guide to field identification. Birds of North America. Golden Press, N.Y. $360 \mathrm{pp}$.

${ }^{7}$ SCOTT, S.L. 1987. Field guide to the birds of North America. National Geog. Soc., Wash. 464 pp.

"UDVARDY, M.D.F. 1977. The Audubon Society field guide to North American birds. Western region. Knopf, N.Y. 855 pp. 